\title{
La jineta indiana \\ en los textos de Juan Suárez de Peralta y Bernardo de Vargas Machuca
}

\author{
Benjamín Flores Hernández
}

Universidad Nacional Autónoma de México

Una vertiente importante de la bibliografía hispánica de los siglos XVI y XVII fue la dedicada a tratar las técnicas y ejercicios de la caballería, particularmente según dos escuelas de andar a caballo, la de la brida y la de la jineta, a la que generalmente se reconoció como la tradicional española. Aquí se analiza la peculiar participación dentro de esa literatura de dos autores indianos, por lo demás de personalidad muy interesante: el criollo novohispano Juan Suárez de Peralta (México, hacia 1537-España, después de 1596) y el capitán baquiano Bernardo de Vargas Machuca (Simancas, hacia 1555Madrid, 1622).

La aventura de la presencia de España en América a partir del año de 1492 — descubrimiento, conquista, colonización - quiso significar, entre otras muchas cosas, y al mismo tiempo que también un ferviente deseo de realizar aquí el mundo ideal hasta entonces sólo soñado en Europa, un afán de copiarse a sí misma en las nuevas tierras. Todo lo que era la vieja España, en su grandeza y en su miseria, en sus creencias y en sus pasiones, en las instituciones que le conferían consistencia y en las mínimas prácticas de la vida diaria, quiso repetirse por entero de este lado del Atlántico. No obstante la existencia de esa presentación, lo producido en el nuevo mundo no pudo menos que desarrollar características propias, que sin hacerlo algo radicalmente diferente sí le conferían rasgos locales que enseguida se destacaban. Era, pues, lo mismo, pero diferente.

Mi intención ahora es referirme a un aspecto particular de este empeño por trasladar a las Indias todo lo hispánico: el relativo a esa manera de andar a caballo tradicional española conocida como de la escuela de la jineta. Para ello, especialmente habré de considerar los textos de dos brillantes escritores indianos de la segunda mitad del siglo XVI y primeros años del XVII, por lo demás ambos poseedores de una apasionante personalidad que los hace manjar suculento para el análisis del historiador: Juan Suárez de Peralta, criollo mexicano, y Bernardo de Vargas Machuca, baquiano peninsular. 


\section{La caballería española de los siglos XVI y XVII}

$\mathrm{Al}$ revisar con cierto cuidado el conjunto de la producción bibliográfica española de los siglos XVI y XVII resalta enseguida lo abundante que, dentro de ella, resulta la dedicada a un tema muy característico: el de la caballería. Y conste que no me refiero ahora a las popularísimas novelas, tan en boga entonces, que daban cumplida cuenta de los Amadises, los Palmerines, los Galaores y demás fauna de héroes legendarios de raigambre medieval, las cuales alcanzaron su más alta cumbre en la del sin par ingenioso hidalgo don Quijote de la Mancha, concebida precisamente por su autor para terminar con ellas; ni tampoco, de manera principal, a la infinidad de composiciones poéticas, obras dramáticas o pasajes narrativos elaborados por muchos de los más destacados escritores de la época, que de alguna manera hicieron alusión a algunos de los múltiples aspectos de la relación hombre-animal equino. Aludo aquí, más bien, a la inmensa multitud de libros técnicos aparecidos en las prensas castellanas y portuguesas durante aquellas dos centurias destinados a la enseñanza de las diferentes formas de montar a caballo características de ese tiempo.

No puede decirse que el tema literario del que ahora se habla haya sido, ni mucho menos, exclusivamente hispánico. Aunque, eso sí, la entusiasta forma de estudiar la materia, el fervor patriótico con que los escritores españoles se lanzaron al análisis de los modos tradicionales de cabalgar propios de su tierra y el particular énfasis que dentro de sus páginas dieron a los enfrentamientos de los caballeros con los toros bravos, sí constituyen una particularidad típicamente hispana de la manera de abordar el asunto.

Primeramente en Italia y más adelante en Francia, desde los iniciales años del siglo XVI empezaron a divulgarse los pricipios de una novedosa escuela de equitación de origen napolitano que postulaba el triunfo de una caballería ligera, rápida, sobre la típica de los últimos tiempos de la Edad Media, la propia de los desafíos y de los torneos, caracterizada por la pesadez de unos equinos abrumados por el fardo de la armadura que protegía tanto a ellos como a quienes los montaban. Juan Arias Dávila Puertocarrero, conde de Puñonrostro, recordaba en su Discurso para estar a la jineta con gracia y hermosura, de 1590, a los principales de esos autores italianos que, ya para entonces, resultaban ampliamente conocidos en España por sus explicaciones sobre la referida manera de cabalgar, conocida en castellano con el nombre de a la brida: 
"de lo cual trataron larguísimamente Federico Grissone, Juan Bautista Ferrero, Claudio Corte de Pavia, César Frasco de Ferrara, tan bien y con tanta elegancia, que admira. Pero sobre todos habló tan altamente Pascual Caracciolo, hermano del duque de Martina; el cual compuso un libro intitulado La gloria del caballo, tan erudito para criar un príncipe cuanto provechoso para doctrinar un caballo". ${ }^{1}$

Entre quienes inauguraron y llevaron adelante la caballería bridona en Francia deben recordarse, no muy posteriores a los mencionados por Puertocarrero, los nombres de la Broue, de Francisco de Noue, de Antonio Pluvinel — creador de la Académie Hippique — y, algo más tarde, de Robichon de la Guérnière. ${ }^{2}$

En España, para 1568 Antonio Flores de Benavides tradujo a Grissone, ${ }^{3}$ bien que para entonces ya debía ser archiconocida la técnica de la brida así en la península cuanto en los dominios castellanos de allende la mar, puesto que dada la continua presencia hispana en Italia no puede suponerse otra cosa. Sin embargo, los tratadistas españoles de aquel tiempo dedicados a estudiar el caballo, su monta, modo de combatir en él y demás temas afines, no sólo hicieron referencia a dicha caballería, sino que también trataron, mostrando una clara preferencia hacia ella, de la de la jineta, que gozaba de gran prestigio en todos los territorios dependientes del rey católico.

Según parece, el primero de los muchos libros aparecidos sobre la enseñanza de la caballería en las imprentas de España y de Portugal a partir de la segunda mitad del siglo XVI y hasta bien entrado el XVIII, fue uno impreso en el año de 1551 en la oficina tipográfica que Cristóbal Alvarez tenía en la ciudad de Sevilla: el Tractado de la cavallería de la gineta de

1 Arias Dávila Puertocarrero, Juan: segundo conde de Puñonrostro: "Discurso de don... para estar a la jineta con gracia y hermosura. Dirigido al príncipe don Felipe nuestro Señor. Con privilegio, Madrid, Pedro Madrigal, 1590"; en Sociedad de Bibliófilos Españoles: Tres libros de jineta de los siglos XVI y XVII. Intr. de C.[esáreo] Sanz Egaña, Madrid, 1951, XLVII, 270 págs.; ils., facs., (Sociedad de Bibliófilos Españoles. Segunda época, XXVI), págs. 1-66, pág. 42. César Frasco de Ferrara es César Fiaschi. El conde de Villamediana, por su parte, recordaba también a los modernos italianos escritores sobre la equitación: "el Covachuelo, el Grison, el Fiaschi, el Corte y el Siliceo" (epístola en Bernardo de Vargas Machuca: "Teórica y exercicios de la gineta, primores, secretos y advertencias della, con las señales y enfrenamientos de los cavallos, su curación y beneficio. Por el governador Don... Dirigida a Don Luis Enríquez, Conde de Villaflor, comendador de Cabeza el Buey. Con privilegio", en Sociedad de Bibliófilos: Tres libros..., págs. 113-270, pág. 124).

2 Sanz Egaña: "Introducción" a Sociedad de Bibliófilos: Tres libros..., págs. XXV y XXVI.

3 "Reglas de la cavallería de la brida, y para conoscer la complesión y naturaleza de los cauallos, y doctrinarlos para la guerra, y servicio de los hombres. Con diversas suertes de frenos. Compuestas por el S. Federico Grisson, gentilhombre napolitano, y ahora traduzidas por el S. Antonio Florez de Benavides, Baeza, Juan Baptista de Montoya, MDLXVIII, en 4o., 145 ff., 4 hh". Ver Sanz Egaña: "Introducción" a Sociedad de Bibliófilos: Tres libros..., pág. XXXV. 
don Fernando Chacón, caballero calatravo. ${ }^{4}$ A continuación, y por espacio de más de ciento cincuenta años, no pararon los talleres de todas las ciudades de la península de tirar textos y más textos con esta temática, varios de los cuales alcanzaron la segunda y aun la tercera impresión. ${ }^{5}$

Fundamentalmente, la intención de estos escritos era la instrucción de los jóvenes. Se pensaba que pocas acciones serían tan beneficiosas para la gloria guerrera de la nación que el adiestramiento de los nuevos ciudadanos en los secretos de la equitación. Y cabe señalar la coincidencia de esta proliferación de tratados sobre las formas de comportarse mejor un caballero sobre su corcel con los tiempos en los que, poco a poco, fue siendo menor y menos brillante la intervención hispana en las campañas europeas y americanas. Sucedió que, ante la disminución de las oportunidades para que los muchachos aprendieran en vivo el arte militar ecuestre, debieron irlo conociendo, cada vez más, por la mera letra de aquellos escritos y, cuando mucho, mediante el simulacro bélico significado por los juegos de cañas y sortijas y por el alanceamiento o rejoneo de cornúpetas. Pocos textos hay tan expresivos acerca del papel representado por la equitación en la formación de los más cabales aristócratas de la época que las siguientes palabras, puestas por Juan Suárez de Peralta en el "Proemio al lector" de su Tractado de la gineta y brida:

"Y pues el caballo es animal tan dócil y apto para enseñarse, no es justo se deje de mostrar tan noble y virtuoso ejercicio, pues del caballo nace el nombre y valor de los caballeros. Por tanto, los nobles tienen la obligación más que los otros, a seguir esta virtud y así no sólo los nobles, mas los viles hombres y bajos, con la fuerza y valor de este animal, se hacen cada día más grandes, más ilustres". ${ }^{6}$

La práctica de la jineta constituía en España, así, actividad por sí misma ennoblecedora; detrás de tal hecho, que enseguida reluce cuando se

4 García-Baquero González, A.; Romero de Solís, P., y Vázquez Parladé, I.: Sevilla y la fiesta de toros, Sevilla, 1980, pág. 153.

5 Para tener una idea de la ingente cantidad de libros y folletos sobre este tema publicados por entonces puede verse la parte referente a los "Libros de jineta y reglas de torear a caballo", del capítulo intitulado "Historia de la preceptiva taurina", que aparece en el tomo II de José María de Cossío: Los toros. Tratado técnico e histórico, varios tomos, Madrid, 1943 y siguientes, ils., fots., láms., tomo II, págs. 4-41, sobre todo. En las págs. 80 a 82 de ese mismo tomo, a modo de apéndice al referido capítulo, hay un útil y esquemático "Indice de obras analizadas en este trabajo". En la lista de "Obras particulares de caballería" de su relación de obras militares del siglo XVII, Francisco Barado (Literatura militar española, por..., post-scriptum de Luis Vidart, Barcelona, Viuda e Hijos de E. Ullostres y Ca., editores, MDCCCXC, 740 págs., ils., pág. 361) incluye trece textos.

6 Suárez de Peralta, Juan: Tractado de la jineta y de la brida, México, 1950, pág. 16. 
adentra uno en el estudio de la época, puede descubrirse fácilmente toda una tradición medieval de hazañas reconquistadoras consumadas sobre los potros propios de los campos andaluces. Don Quijote, tenido por loco al intentar a sus más de cincuenta años vivir en la realidad las increíbles fantasías de unas novelas pobladas de irreales encantadores y gigantes y en las cuales el vicio y la virtud se representaban con características maniqueas que de ningún modo correspondían al mundo efectivo en el que se estaba, más desbarraba en sus excentricidades cuando, para defender la causa de su caballería andante, partía de unos argumentos con los que todo mundo no podía menos que encontrarse de acuerdo y en los cuales cualquier español de su tiempo hallaba motivos sobrados para identificar sus propios ideales, bien que dándose cuenta de la imposibilidad de hacerlos cumplideros en la existencia cotidiana. O sea: no era por lo caballero por lo que se tenía por de cerebro seco al bueno de Alonso Quijano, sino por intentar portarse como tal de una forma distinta a la común de la época siendo, además, que no contaba con los medios de fortuna suficientes para mantener esa su profesión de caballería con el necesario decoro cortesano que por entonces se consideraba intrínsecamente unido a ese estado. La defensa de su posición por parte del famoso manchego, que resultaba magnífica e irreprochable en buena lógica, tenía como base de sustentamiento el pleno favor de que gozaban, a la vista de todos, los ejercicios caballerescos ejecutados en la plaza pública:

"Bien parece un gallardo caballero [—empezaba diciendo- ], a los ojos de su rey, en la mitad de una gran plaza, dar una lanzada con felice suceso a un bravo toro; bien parece un caballero, armado de resplandecientes armas, pasar la tela en alegres justas delante de las damas, y bien parecen todos aquellos caballeros que en ejercicios militares, o que lo parezcan, entretienen y alegran, y, si se puede decir, honran las cortes de sus príncipes; pero [-y aquí pasaba a defender su propia cristiana actividad desfacedora de entuertos, tras de recordar el universal aplauso hacia aquellas funciones de caballería moralmente intrascendentes-] sobre éstos parece mejor un caballero andante, que por los desiertos, por las soledades, por las encrucijadas, por las selvas y por los montes anda buscando peligrosas aventuras, con intención de darles dichosa y bien afortunada cima, sólo por alcanzar gloriosa fama y duradera; mejor parece, digo, un caballero andante socorriendo a una viuda en algún lugar despoblado que un cortesano caballero requebrando a una doncella en las ciudades"?

7 Cervantes Saavedra, Miguel de: El ingenioso hidalgo don Quijote de la Mancha, est. prel. y notas por Federico de Onís, 2 vols., México, 1963, retr., facs., (Clásicos Jackson, 6 y 7), vol. II, pág. 147.

Tomo LIV, 2, 1997 
Conviene hacer la advertencia de que en todos los países europeos de la época existía por entonces un amplio interés por la equitación, ejercicio tan indispensable para la guerra, y que los nacionales de cada estado creían ser superiores a los demás en cuanto a su dominio sobre el caballo. En Francia, por ejemplo, el escéptico y moderado Miguel de Montaigne, por cierto nunca demasiado chauvinista, no tenía empacho en declarar en el capítulo XLVII del libro I de sus Ensayos, su creencia en que "ninguna nación nos aventaja en el acertado manejo de este animal". ${ }^{8}$

\section{Las escuelas de la jineta y de la brida}

Desde finales del siglo $\mathrm{XV}$, al quedar en desuso las formas pesadas de caballería caracterizadas por hombres y animales cubiertos de enormes armaduras que más que nada parecían fortalezas ambulantes, fueron dos los principales modos de andar a caballo utilizados en guerra y en paz por los militares españoles, que por cierto fueron quienes irrumpieron en las campañas italianas de los últimos años del cuatrocientos con un nuevo concepto de la batalla, así en cuanto a la actuación de los de a pie como a la de los de a caballo, ambos sectores interviniendo coordinadamente, en un estilo de guerrear definido por la rapidez y la movilidad envolvente de los combatientes: la brida y la jineta.

En realidad, la técnica tradicionalmente española de montar sobre los corceles era la conocida como de la jineta, y fue ella, precisamente, la que al aparecer en los campos napolitanos en las luchas allí emprendidas por el rey de Aragón a lo largo del siglo que corre entre 1420 y 1520, trastornó todo el sentido del enfrentamiento caballeril propio de la Edad Media y del primer Renacimiento. Según Cesáreo Sanz Egaña, el origen y la peculiaridad de esa forma de cabalgar debe buscarse, antes que en detalles de longitud de estribos o de formas de la silla, en la anatomía típica de los equinos peninsulares, de menor tamaño y mayor nerviosidad que los nativos de otras latitudes del continente europeo. ${ }^{9}$

8 Montaigne, [Miguel Eyquem de]: Ensayos, selec., trad., est. prel. y notas por Ezequiel Martínez Estrada, México, 1963, pág. 128.

9 En la "Introducción" a los Tres libros de jineta... publicados por la Sociedad de Bibliófilos Españoles (págs. XII y XIII), caracteriza Cesáreo Sanz Egaña al caballo español el cual, según su teoría, es el que, por su forma de ser, posibilitó el desarrollo de la monta de la jineta. 
Etimológicamente, la palabra jineta se deriva, según han demostrado varios eruditos filólogos, del nombre de una tribu berberisca, la de los zenotes —zânati, los originarios de Zânata—, una partida de los cuales arribó a tierras peninsulares hacia el 1263, con la intención de ponerse al servicio del rey Muhámmad I de Granada, en lucha con Alfonso X de Castilla. ${ }^{10}$

Estos zenotes debieron haber sido muy diestros guerreros de a caballo, y pronto hicieron que su nombre gentilicio pasara a las diferentes lenguas usadas en Iberia - al castellano, al catalán, al portugués-, transformándose la $z$ inicial en $j$, como sinónimo de "soldado de a caballo que ataca súbitamente y huye si no puede herir mortalmente" sión, en femenino, como la denominación de una raza específica de jacas, la empleada por ellos, útil para ese tipo de ataque sorpresivo o, también, la lanza corta que esgrimían los individuos de ese grupo de africanos belicosos. ${ }^{12}$

Por su parte, la caballería a la brida parece haberse originado en la Italia del sur, quizás como la inventada allí tras la llegada de los ligeros jinetes españoles, en el afán de conferir a corceles más grandes y torpes que los arábigoandaluces las mismas características de agilidad propias de éstos. El nombre más antiguo de este tipo de monta fue el de a la estradiota, voz derivada de los stradiotti, caballeros mercenarios de nacionalidad albanesa que servían en el ejército veneciano, los cuales debieron haber sido los primeros en tratar de aplicar los principios de la caballería ligera en el uso de equinos centroeuropeos. En una cita de Clonard transcrita por José Almirante en su Diccionario militar, se apuntan algunas notas sobre estos militares de paga:

"El 20 de julio de 1507 hizo parte de la caballería española un nuevo cuerpo conocido con el nombre de estradiotes. Fue esta una compañía de caballos ligeros que al mando del capitán don Fernando Valdés, vino desde Italia acompañando al rey

10 Véase Ibídem, pág. VIII, nota 1, y Corominas, Joan: Diccionario crítico etimológico castellano e hispánico, con la colaboración de José A. Pascual, Madrid, 1980-1991, vol. III, págs. 517 y 518.

11 Ibídem. La nota correspondiente a la evolución de la palabra jirafa, cuya $j$ inicial también fue originariamente $z$ en español, según Corominas, está en Ibídem, vol. III, pág. 521.

12 Ibídem, vol. III, págs. 517 y 518. Véase también Almirante, J.: Diccionario militar; etimológico, histórico, tecnológico, con dos vocabularios francés y alemán, Madrid, 1869, XIV, págs. 733 y 734. Como se sabe, en la actualidad la palabra jinete ha llegado a significar sólo "hombre que anda a caballo" en general, sin mayor indicación de estilo o circunstancia. Es curioso señalar que jineta es, también, una "especie de gaduña [—mamífero emparentado con la marta—] africana y española" (Corominas: Diccionario..., vol. III, pág. 516. 
Fernando V; estaba formada y organizada al mismo modo de los cuerpos de esta clase, que, al servicio de los venecianos, militaban en la Morea y Albania. Sus armas defensivas eran un bacinete con que cubrían la cabeza, y el alpartaz, sobre el cual llevaban el cejaco que no era otra cosa que el jaco o jaquetón de que hemos hablado en otra parte, y las ofensivas la lanza, espada, martillo de amor y tablachina". ${ }^{13}$

Según Almirante, la más profunda etimología de esta palabra debe emparentarla con la italiana strada - camino-, puesto que la forma de operar de los estradiotas se correspondía en buena medida con la del coureur o batteur d'estrade francés: ${ }^{14}$ lo que parece no recordar Almirante es que la voz griega stratiótes* quiere decir soldado, derivada a su vez de stratiá, ${ }^{* *}$ ejército. ${ }^{15} \mathrm{El}$ nombre de a la brida, con el cual posteriormente fue identificada esta manera de montar debió originarse en el hecho de que, en ella, resulta parte fundamental el control de la bestia precisamente por medio de la brida, es decir, como dice el Diccionario de la Academia, el "freno del caballo con las riendas y todo el correaje, que sirve para sujetarlo a la cabeza del animal". ${ }^{16}$

Así, pues, en cuanto a su origen, puede definirse muy bien a la jineta como la escuela ecuestre tradicional española - hispanoárabe, para ser exactos-, correspondiente a un preciso tipo de equinos - los andaluces de la actualidad - pequeños, recogidos y con un peculiar modo de andar y conducirse fácilmente identificable; y a la bridona, como la primera caballería ligera extraespañola del Renacimiento, surgida en mucho por el deseo de emular las hazañas de los caballeros hispanos en tierras italianas, sólo que utilizando cabalgaduras de tipo distinto a las empleadas por ellos, las cuales, precisamente por sus caracterísaticas de mayor reposo y pesadez, requerían de una doma más ardua que la propia de la jineta, mucho más natural. Sin embargo, la situación se complicó inevitablemente tiempo después, al tratar de aclimatarse, a su vez, la escuela bridona en España, tras el éxito alcanzado por ella en Nápoles y Sicilia. Se dio entonces el caso curioso de pretender los españoles enseñar a sus caballos los trucos y artimañas que italianos y franceses habían mostrado a los suyos para hacer que sus evoluciones se parecieran lo más posible a las de los animales hispáni-

13 Almirante: Diccionario..., págs. 452 y 453.

14 Ibídem.

* $\sigma \tau \rho \alpha \tau \imath \omega ́ \tau \eta s$.

** $\sigma \tau \rho \alpha \tau \imath \dot{\alpha}$.

15 Corominas: Diccionario..., vol. II, pág. 437. pág. 229.

16 Real Academia Española: Diccionario de la lengua española, Madrid, 1992, XXXI, 
cos. ${ }^{17}$ Cuando alguien en España se refería a estas dos diferentes maneras de equitación no pensaba que debieran aplicarse a dos tipos disímiles de brutos; para diferenciarlas se atendió a las peculiaridades externas más notorias de cada una; entre éstas, la que llamó más la atención fue la de la diversa longitud de los estribos y la consecuente disposición de las piernas, y así ya Sebastián de Covarrubias y Orozco, en pleno siglo XVII, se refería en su Tesoro de la lengua catellana o española, de 1611, a cada una de las dos de la siguiente manera:

Estradiota: "un género de cavallería, de que usan en la guerra los hombres de armas, los quales llevan los estrivos largos, tendidas las piernas, las sillas con borrenes, do encaxan los muslos y los frenos de los cavallos con las camas largas; todo lo qual es al revés en la gineta". ${ }^{18}$

Jineta: "género de caballería africana, con frenos o bocados recogidos y estribos anchos y cortas aciones, a éstos llaman ginetes y a esotros bridones, los cuales llevan los estribos largos y la pierna tendida, propia caballería para hombres de armas". ${ }^{19}$

En términos generales, las mismas definiciones son las seguidas hasta ahora por la mayoría de los autores, entre ellos la Real Academia de la Lengua, que en la edición de 1992 de su Diccionario todavía dice de la estradiota ser la "manera de andar a caballo con estribos largos, tendidas las piernas, las sillas con borrenes, donde encajan los muslos, y los frenos de los caballos largos", ${ }^{20}$ y de la jineta corresponder al "arte de montar a caballo que, según la escuela de este nombre, consiste en llevar los estribos cortos y las piernas dobladas, pero en posición vertical desde la rodilla abajo". ${ }^{21}$

La técnica de la brida, que alcanzó su mayor apogeo en España a lo largo de todo el siglo XVI, llegando en algún momento hasta poner en peligro la constante preeminencia de la jineta, fue luego declinando en popularidad en el curso de la centuria siguiente. En realidad, sucedía que a pesar de reconocerse su origen foráneo, morisco, era común la aceptación de la caballería jineta como la forma más castiza, tradicional española, de andar sobre un corcel. Se sabía muy bien que Enrique IV de Castilla, por ejem-

17 Sanz Egaña (“Introducción” a Tres libros..., pág. XXXIX) habla de cómo, para él, la escuela bridona no fue sino el intento de obligar a los caballos septentrionales a adquirir determinadas características naturales en los meridionales de moros y españoles.

18 Citado en Corominas: Diccionario..., vol. II, pág. 795.

19 Citado en Cervantes: El ingenioso hidalgo..., vol.I, pág. 385, nota 2.

20 Real Academia: Diccionario..., pág. 647.

21 Ibídem, pág. 851. 
plo, había sido gran practicante de esta escuela de monta, ${ }^{22}$ y de don Fernando el Católico anotó Hernando del Pulgar que

"Caualgaba muy bien a caballo en silla de guisa de la jineta, justaba sueltamente e con tanta destreza, que ninguno en todos sus reynos lo hacia mejor". ${ }^{23}$

Fernando Chacón, hacia 1551, en plena época cenital de la brida, proclamaba la raigambre nacional de la otra silla, instando a sus compatriotas a devolverle su antiguo brillo y recordándoles cómo con ella habían consumado sus grandes hazañas los mayores de los caudillos hispanos y cómo, ejercitándola

"los católicos y bienaventurados reyes, de gloriosa memoria, ganaron y sojuzgaron nuestros reinos de España. Y el Rey Católico, nunca se hallará que en ninguna guerra que tuvo anduviese sino a la gineta. Y asimismo el Gran Capitán Gonzalo Fernández, y con ella ganó dos veces Italia. Y así mesmo muchos señores y grandes destos reinos nunca se hallaron en cosa de guerra sino a la gineta; y con ella les dio Dios grandes victorias y vencimientos de sus enemigos". ${ }^{24}$

En un primer acercamiento a la materia podría llegar a suponerse que la participación aristocrática en los ejercicios ecuestres alcanzara una validez intrínseca. Empero, profundizando en el tema, se viene a descubrir que la verdad es que esos deportes de equitación no pretendían ser, en realidad, sino una especie de ensayo para el aprendizaje de algo que era en la guerra donde debía mostrar su más auténtica y ejemplar aplicación. El más hondo sentido que tenía la multitud de obras y opúsculos editados por aquella época para la explicación de las diversas técnicas de andar a caballo era el de enseñar cómo, sobre ese animal, habrían de continuar los españoles la realización de sus gloriosas acciones militares a todo lo ancho y largo del mundo. Tal cosa la indicaba claramente, por ejemplo, Juan Suárez de Peralta en su Tractado..., cuando se refería a los valiosos servicios bélicos prestados a los caudillos de su patria por los corceles puesto que, argumentaba allí:

"No hay fiesta cumplida, ni juego valeroso, ni batalla grande donde él no se halle. Con ellos los reyes, príncipes y grandes señores defienden sus tierras y conquistan las ajenas". ${ }^{25}$

22 Véase Contreras, J. de: marqués de Lozoya: Los orígenes del Imperio. La España de Fernando e Isabel, 1966, pág. 21.

23 Pulgar, Fernando del: Claros varones de Castilla, Buenos Aires, 1948, pág. 133.

24 Citado en Cossío: Los toros..., tomo IV, págs. 831 y 832.

25 Suárez de Peralta: Tratado de la jineta..., pág. 16. 
Triunfante en definitiva en la península ibérica la técnica de la jineta, quedó prácticamente como única señora en campos y plazas durante todo el siglo XVII, hasta el momento del advenimiento al trono de la dinastía de los Borbones, con quienes habrían de cambiar radicalmente las cosas. No resultó nada extraño que quien se hallara en condiciones económicas de hacerlo, como el legendario conde de Villamediana, llegara a gastar auténticas fortunas en su afán de importar desde Berbería o Arabia los mejores equinos aptos para ejercitarla. ${ }^{26}$

Aparte de su utilización en las campañas militares, la principal actividad en la cual habían de practicarse las reglas y disposiciones de la caballería expuestas en los tratados fue, en España, durante las centurias décimoquinta y décimosexta, la de las corridas de toros. El punto culminante, la acción más emocionante, de más riesgo, belleza y significación de las realizadas entre los tablados de una plaza pública en tiempos de la monarquía de los Austrias, resultaba la de liquidar un bravo bovino con lanza.

A partir de la vieja costumbre de los torneos y justas medievales, de fuerte arraigo en toda la Europa feudal, se desarrolló grandemente en España el llamado juego de cañas, que esencialmente era un combate simulado en el cual las mortales lanzas se habían trocado en cañas más o menos inofensivas, las cuales debía romper el participante en la adarga - escudo- de su oponente. Por lo demás, la escuela de la brida buscó mucho amaestrar a los corceles para determinadas habilidades específicas, tales la de cocear con gracia ${ }^{27} \mathrm{o}$ la de hacerlos evolucionar siguiendo determinados círculos y figuras. ${ }^{28}$

\section{Trasplante en América}

El caballo pasó a Indias junto con las primeras empresas conquistadoras, en las cuales enseguida mostró su indiscutible utilidad. Son continuas las referencias de comentaristas e historiadores acerca de los servicios prestados a los castellanos por este animal en las entradas expedicionarias en demanda de la expansión de los dominios de su soberano a través de

26 Véase al respecto Sáenz-Alonso, Mercedes: Don Juan y el donjuanismo, Madrid, 1969, págs. 236 y 237.

27 Suárez de Peralta: Tratado de la jineta..., pág. 95, capítulo XV de la parte que se refiere a la brida, "Que trata cómo se han de mostrar las coces al caballo".

28 Ibídem, págs. 118 y 119. 
toda la geografía del nuevo continente. Recuérdese cómo, en múltiples sitios, tardaron los indios un buen rato en salir de su asombrada creencia en que hombre y bestia conjuntaban una sola unidad. Hasta Santiago el Mayor se dice que anduvo en varias batallas auxiliando a sus fieles ibéricos, montado en su caballo blanco — rucio picado lo vieron en Cintla, según Francisco de Gómara- ${ }^{29}$ Ya en tiempos de paz e instaurada la vida española en los diversos reinos indianos, allí se desarrollaron, junto con las demás costumbres metropolitanas, las de los deportes caballerescos. En varios lugares me he referido, por ejemplo, a la instauración de las solemnidades anuales de San Hipólito, Santiago y Santa María de Agosto en la ciudad de México, desde 1528, con muerte de astados y paseos ecuestres; ${ }^{30}$ ahora sólo voy a recordar lo que decía Bernal Díaz de que, en las celebraciones organizadas para 1539 por Cortés y el virrey Mendoza en México con motivo de la paz de Aguas Muertas entre el césar Carlos y Francisco I de Francia, su primo, hubo

"grandes fiestas y regocijos; y fueron tales, que otras como ellas, a lo que a mí me parece, no las he visto hacer en Castilla, así de fiestas y juegos de cañas, y correr toros, y encontrarse unos caballeros con otros, y otros grandes disfraces que había en todo", ${ }^{31}$

y de que, entre los indígenas, debido a la obra consumada por él mismo y por sus compañeros, para el tiempo en que escribía, principios del último tercio del siglo XVI,

"todos los más caciques tienen caballo y son ricos, traen jaeces con buenas sillas y se pasean por la ciudad y villas y lugares donde se van a holgar y son naturales, y llevan sus indios y pajes que les acompañan, y aun en algunos pueblos juegan cañas y corren toros y ponen sortija, especial si es dìa de Corpus Christi, o de Señor San Juan, o Señor Santiago, o de Nuestra Señora de Agosto, o la advocación de la iglesia del santo de su pueblo; y hay muchos que aguardan los toros aunque sean bravos y muchos de ellos son jinetes, y en especial en un pueblo que se dice Chiapa de los indios". ${ }^{32}$

29 López de Gómara, Francisco: Historia general de las Indias. Barcelona, 1985, tomo II, pág. 40.

30 Así en mi tesis de licenciatura: Con la fiesta nacional, por el siglo de las luces. Un acercamiento a lo que fueron y significaron las corridas de toros en la Nueva España del siglo XVIII, trabajo que presenta Benjamín Flores Hernández para pretender el título de licenciado en Historia, México, Universidad Nacional Autónoma de México. Facultad de Filosofía y Letras, 1976, 339 págs., págs. 19 y 20.

31 Díaz del Castilllo, Bernal: Historia verdadera de la conquista de la Nueva España, intr. y notas de Joaquín Ramírez Cabañas, México, 1976, pág. 544.

32 Ibídem, pág. 582. 
Antes de ajustarse el primer centenario del descubrimiento colombino, ya estaba completamente aclimatada la caballería a la española en la nueva masa continental incorporada a la conciencia europea. Un oriundo americano, Juan Suárez de Peralta, fue, según el capitán Vargas Machuca, "el más único caballero de la silla jineta que ha tenido el mundo". ${ }^{33} \mathrm{Y}$ recorriendo los libros del propio Vargas Machuca se encuentran numerosas referencias a su admiración por corceles y jinetes americanos, llegando a hablar de una específica "jineta de las Indias", escuela de andar a caballo con características muy propias. ${ }^{34}$ Ya lo apuntaba con toda certeza en el prólogo al Libro de exercicios de la gineta:

"que aunque es verdad que Berbería dio a España principio della [— de la caballería de la jineta-], y España a las Indias, en esta parte se ha perfecionado más que en otra". ${ }^{35}$

En cuanto a la forma en que se habían extendido muy pronto los équidos por las llanuras del Nuevo Mundo, expresaba en su libro de la Milicia... el propio autor el hecho cierto de que

"Los caballos, que fue el más noble animal y de más provecho, quiso Dios multiplicasen mucho, y es tanto que no hay español que no lo alcanza y aun los indios en general en las tierras asentadas; [...] este animal es de más servicio que en estas partes [-escribía en la península—], porque las arrias o recuas, en la mayor parte, son de caballos, porque para cargas se sirven poco de mulas, si no es en Tierra Firme. Hay extremados caballos de regocijo y las caballerizas están bien pobladas. Los mejores son los mexicanos pero en general a una mano son buenos, porque demás de ser ligeros y de maravillosas carreras, son bien arrendados y sujetos al castigo, sin resabios ni brújulas como los de estas partes y crían mejores y más fuertes cascos. Sólo tienen una falta, que son pisadores, y de aquí viene correr bien, que como son terreros, atropellan mejor y son más ligeros, y de catorce años no es un caballo viejo". ${ }^{36}$

Y acerca de la destreza de ciertos caballistas americanos, y muy particularmente novohispanos, existe entre otras la noticia que sobre ella apun-

33 Vargas Machuca: Teórica y exercicios..., págs. 148 y 149.

34 Así, cuando en la Teórica y exercicios... (Ibídem, pág. 156) apuntaba que "el conde viejo de Puñonrostro[...] en muchas cosas sigue[...] la jineta de las Indias, en que muestra bien la verdad della".

35 Vargas Machuca, Bernardo de: Libro de exercicios de la jineta, compuesto por el Capitán D..., Indiano, natural de Simancas en Castilla la Vieja. Dirigido al conde Alberto Fúcar, Madrid, Pedro Madrigal, 1600, [16] + 120 fojas, ils., foja sin número.

36 Vargas Machuca, Bernardo de: Milicia y descripción de las Indias, escrita por el capitán D... Caballero castellano, natural de la villa de Simancas. Reimpresa fielmente, según la primera edición hecha en Madrid en 1599, con unas "Noticias sobre la vida y obras del capitán D. Bernardo de Vargas Machuca", Madrid, 1892, vol. II, págs. 122 y 123. 
tara su paisano Suárez de Peralta, quien al hablar en su Tractado... de los mejores corredores de lanzas a la brida, afirmaba que

"En toda Italia y España se corre a lo cierto, aunque no tan galán, como en la Nueva España, a causa de que se han ejercitado muy mucho los caballeros de allá, añadiendo nuevas maneras de sacar la lanza, dándole extremadísimo aire. Y es tanta la curiosidad de ellos, que para perfeccionarse en este arte mancan los caballos en que han de correr lanzas desjarretándolos de un pie y el que viene a ser manco de esparavanes le estiman mucho $[\ldots]{ }^{\prime 37}$

Y allí va otro testimonio, por demás egregio, de la fama alcanzada por los caballeros de México. Es nada menos que de Miguel de Cervantes Saavedra y viene en palabras de Sancho Panza, quien las exclamó cuando fue a contar a su señor lo sucedido en su encuentro con la hermosísima Dulcinea del Toboso, transformada en zafia labradora por artes de encantamiento:

“—iVive Roque, que es la señora nuestra ama más ligera que un alcotán, y que puede enseñar a subir a la jineta al más diestro cordobés o mexicano!". ${ }^{38}$

Para tratar aquí de la manera específica que tuvo de practicarse la equitación en Indias se analizan particularmente el Tractado de la cavallería de la gineta y brida, del inquieto criollo mexicano Juan Suárez de Peralta, y los tres sucesivos libros compuestos sobre ese tema por el simanquino Bernardo de Vargas Machuca. Asimismo, se utilizan también unas cuantas de las expresiones del Discurso para estar a la jineta con gracia y hermosura - Madrid, 1590_, de Juan Arias Dávila Puertocarrero, conde de Puñonrostro, de quien se dijo que "en muchas cosas sigue la gineta de las Indias"39 y del Modo de pelear a la gineta - Valladolid, 1605-, de Simón de Villalobos, tal vez mexicano como su hermano Diego, que fue quien llevó este escrito a la imprenta.

Con respecto a la importancia de la utilización de los equinos en Indias puede empezarse citando lo que Suárez de Peralta contaba al conde de Medina Sidonia, en la dedicatoria de su libro, acerca de la imapreciable ayuda ofrecida por las cabalgaduras en las batallas con las que España se apoderara de los más grandes imperios americanos. Muy concretamente, en la captura de México y de todo el reino de la Nueva España, puesto que su colaboración fuera en

37 Suárez de Peralta: Tratado de la jineta..., págs. 141 y 142.

38 Cervantes: El ingenioso hidalgo..., vol. II, pág. 90.

39 Vargas Machuca: Teórica y exercicios..., pág. 156. 
"muy gran servicio y fortaleza en sus reinos [del soberano español]: especialmente en la India como vuestra excelencia habrá sido informado que los conquistadores de ella en la pacifiación y toma de la ciudad de México, y reinos y provincias de ellas, ninguna cosa fue tan temida de los contrarios, ni más efecto hizo en ellos, que los caballos, mediante los cuales (con el auxilio divino) y el buen celo y deseo de los que en ella iban, de servir a Dios y a su rey, consiguieron tan alta victoria". ${ }^{40}$

Por su parte, Bernardo de Vargas se refirió varias veces en la Milicia indiana al sitio primordial correspondiente a los caballos en las entradas sobre los aborígenes, afirmando que "donde se pueden aprovechar de ellos, todo lo asegura y deshace". ${ }^{41}$

Las alusiones a la eminente trascendencia militar de los libros de equitación no son nada escasas en el contenido de los referidos textos. Así, cuando el conde de Puñonrostro dedicó su Discurso... al príncipe Felipe dijo haberlo hecho, entre otras cosas, "pues está V. A. obligado a favorecer las cosas del arte y hábito militar". ${ }^{42}$ Y el conde de Villamediana, en la epístola que prologa la Teórica y exercicios... de Vargas Machuca, asentó a su vez la esperanza en que la lectura de ese libro sirviera

"para que, siguiendo su exemplo y doctrina, ningún español dexe de arribar al palio de la virtud heroica, política y militar". ${ }^{43}$

Asimismo, en la licencia real concedida al trabajo de don Juan Arias Dávila se hacía énfasis en que éste era un "libro necesario para el arte militar", ${ }^{44}$ y en la otorgada al de don Juan Suárez de Peralta se mencionaba también cómo

"por parte de vos [...], nos fue hecha relación diciendo que vos habíais compuesto un libro de la arte de caballería de la jineta y brida, para que las personas que a ello se dieren, ejerciten bien el arte militar, el cual era muy útil y provechoso $[\ldots] " .{ }^{45}$

40 Suárez de Peralta: Tratado de la jineta..., pág. 13.

41 Vargas Machuca: Milicia..., vol. I, pág. 192. También decía que "los caballos son buenos y de provecho entre los infantes, aunque sea el número grande entre los contrarios" (Ibídem, vol. I, pág. 146).

42 Arias Dávila: Discurso..., pág. 14.

43 Epístola del conde de Villamediana [don Juan de Tassis y Peralta] al autor. Vargas Machuca: Teórica y exercicios..., pág. 119.

44 Licencia otorgada en San Lorenzo a 21 de julio de 1592. En Arias Dávila: Discurso..., pág. 5.

45 Licencia real, refrendada por Antonio de Eraso. Madrid, 11 de diciembre de 1579. En Suárez de Peralta: Tratado de la jineta..., pág. 11. 
En cuanto al volumen de don Simón de Villalobos, en su propio título llevaba la explicación de ser la enseñanza de un Modo de "pelear" a la jineta; y por si fuera poco, al concederle el permiso para su publicación Juan de Amezcueta, por mandato del rey, hacía ver cómo ese libro de mano que él había revisado, nada menos que

\begin{abstract}
“trataba cómo se habían de aprovechar los caballeros y jinetes fronterizos, del uso de la lanza y adarga en los recuentros y escaramuzas que hacían con los moros, enemigos de nuestra sancta Fe Católica, el cual por ser tan útil y provechoso al bien universal y particular de la Nobleza española, por los documentos que en él se daban, y no haber escripto ninguno hasta agora en este propósito, deseando vos el aumento y enseñanza de los caballeros y soldados, que por exaltación de nuestra Sancta Fe y servicio nuestro salían en desafíos y combates con los moros, que era el particular principal de que el dicho libro trataba $[\ldots]^{146}$.
\end{abstract}

En las campañas americanas, cuando se entró a caballo sobre los indígenas, fue el estilo de montar a la jineta el utilizado, y así aseguraba el Inca Garcilaso cómo esa tierra "se ganó a la jineta". ${ }^{47}$ Vargas Machuca continuamente repite en su Milicia el consejo de que en las conquistas americanas sólo se utilicen las

"sillas jinetas y no se consienta brida, porque con menos riesgo se vadea un río a la jineta y son más prestos al ensillar y se hacen hombres de a caballo". ${ }^{48}$

\title{
La brida y la jineta en Juan Suárez de Peralta, criollo mexicano
}

Nació este hombre hacia 1536 ó 1537 en México, la lacustre ciudad que para entonces apenas contaba con tres lustros de haber sido conquistada a sangre y fuego por Hernán Cortés. Por cierto que era sobrino político del caudillo extremeño, hijo de Juan, hermano de Catalina Xuárez o

46 Licencia real, expedida por mandado de su majestad por Juan de Amezcueta en Lerma, a primero de septiembre de 1604. En Villalobos, Simón de: Modo de pelear a la gineta. Compuesto por Don... y hecho imprimir por don Diego de Villalobos y Benavides, su hermano. Dirigido a la muy Noble y muy leal Ciudad y Caualleros de Xerez de la Frontera. Con privilegio, Valladolid, en casa de Andrés de Merchan, 1605; pág. 70.

47 Citado en Morales Padrón, Francisco: Historia del descubrimiento y conquista de América, Madrid, 1973, pág. 221.

48 Vargas Machuca: Milicia..., vol. I, págs. 145 y 146. En otro lugar recomendaba que los corceles a utilizar en los combates indianos "estén ensillados a la jineta, sin petral ni grupero, y el freno colgado al arzón” (Ibídem, vol. I, pág. 212). 
Suárez, "la Marcaida", primera esposa de Cortés. Su madre se llamó Magdalena de Peralta. En alguna ocasión, junto con sus hermanos fue acusado ante la Inquisición de "ser recién convertidos del Alcorán y secta mahomética".

Formó parte de la primera sociedad criolla novohispana, la de aquellos españoles americanos que, por su cercana parentela con quienes habían ganado la tierra para el rey, se sentían con todos los derechos para usufructuarla con exclusión de cualesquiera otros gachupines apenas llegados de ultramar. Vivió muy alegremente su juventud y primera madurez, en tanto la Corona no puso tasa al disfrute de la abundancia económica de los descendientes de los conquistadores. No queda muy clara su participacion en la llamada "conjuración" de Martín Cortés, aunque lo cierto es que acompañó hasta el patíbulo a los hermanos Avila, condenados por su participación en ella durante 1566.

Permaneció en la Nueva España hasta 1579, cuando pasó a la península, parece que en busca de mejores aires para el género de vida libre que le gustaba, cuyo ejercicio en Indias se había dificultado grandemente por las medidas adoptadas por Felipe II después de la frustrada rebelión crio1la. La última noticia de su vida lo sitúa en España durante 1596, cuando una sentencia obligó a los herederos del marqués del Valle de Oaxaca a pagar a los hermanos Suárez de Peralta y a una prima hermana de éstos 40 mil pesos, aunque él se desistió entonces del pleito.

Aunque en la actualidad el más conocido de los libros escritos por él es el Tratado del descubrimiento de las Indias y su conquista, y de los ritos y sacrificios y costumbres de los indios; y de los virreyes y gobernadores, especialmente en la Nueva España, y del suceso del marqués del Valle segundo, Martín Cortés; de la rebelión que se le imputó, y de las justicias y muertes que hicieron en México los jueces comisarios que para ello fueron por su majestad; y del principio que tuvo Francisco Drake para ser declarado enemigo, editado en todo o en parte varias veces a partir de 1878, el único que logró dar a la imprenta en vida fue el Tractado de la cavallería de la gineta y brida, en el cual se contienen muchos primores, assí en las señales de los cavallos, como en las condiciones, colores y talles, y cómo se ha de hazer un hombre de a cavalllo de ambas sillas, y las posturas que ha de tener, y manera para enfrenar, y los frenos que en cada silla son menester, para que un cavallo ande bien enfrenado: y otros avisos muy principales y primos, tocantes y vigentes a este exercicio, impreso en Sevilla, en casa de Fernando Díaz, durante 1580. 
En este apartado haré un resumen de las consideraciones asentadas en este texto por Juan Suárez, sobre todo en lo que toca a las diferencias entre las montas de la brida y de la jineta. Para ello, me baso en su reedición de México, 1950, hecha por José Alvarez del Villar. De todos modos, conviene recordar que el propio autor compuso otro texto acerca de los caballos, particularmente en cuanto a su biología y curación de sus enfermedades: el Libro de alveitería..., en el cual se contienen muchos primores tocantes a la alveitería nunca vistos ni oydos ni escriptos por autor ninguno, moderno, ni antiguo; especialmente lo ques curar a los cavallos, y todas bestias de pata entera por pulso y orina, y dónde se le hallará el pulso, y cómo se conocerá la orina, y cuándo demuestra por ella augmento de sangre y crecimiento de umores, y los colores que demuestra en materia de alveitería, no puestos en prática ni en theórica, sacado por esperiencia..., el cual debió permaneccer sólo manuscrito hasta 1953, cuando se publicó en México, precisamente por una llamada Editorial Albeitería. ${ }^{49}$ El Tractado... de Suárez de Peralta está dedicado a don Alonso Pérez de Guzmán el Bueno, duque de Medina Sidonia, conde de Niebla y marqués de Cazaza, a quien llama "deudo suyo".

Entre los estudios sobre la caballería compuestos en aquellos años, quizás sea el de Suárez de Peralta, que desde su mismo título hace alusión a que habrá de referirse a ambos tipos de cabalgata, aquel en el cual puedan hallarse más elementos para aprender a diferenciarlos, para entender qué era lo más característico de cada uno de ellos. Allí, por ejemplo, ya desde el "Proemio al lector" ha de hallarse noticia cabal de la procedencia extranjera de la brida, de la cual indica don Juan cómo "crece grandemente en Italia y particularmente en el Reino de Nápoles". ${ }^{50}$ Poco más adelante, aparece una amplia descripción de las características que, en su concepto, deberían corresponder respectivamente a los équidos propicios para cada estilo. Primero, el de la brida, algo mayor sobre todo de barriga, y de maneras más reposadas y fuertes:

"Para la brida es mejor la cabeza para el encuentro larga, angosta y seca, algo carnuda. Ha de tener las crines ralas y largas y si son crespas, mejor. La cruz aguda, extendida, derecha y que en ella muestre el partimiento de la espalda, el sillar corto e igual, los

49 Acerca de la vida de Suárez de Peralta puede verse el estudio preliminar de Teresa Silva Tena que viene en la edición del Tratado del descubrimiento de las Indias. (Noticias históricas de la Nueva España), est. prel. y notas de Teresa Silva Tena, México, 1990, 275 págs., (Cien textos fundamentales para el mejor conocimiento de México).

50 Suárez de Peralta: Tratado de la jineta..., pág. 15. 
lomos redondos y son mejores cuando son más llanos hacia las caderas: los cuales lomos se requieren ser acanalados por medio, la barriga larga y grande con la proporción que se requiere, las ijadas llenas y también el remolino natural que allí cerca en cada una de ellas se halla, cuanto más sale sobre el cuadril (que está frontero el uno del otro) es muy buena señal y muestra ser el caballo ligero, las ancas redondas y de arriba llenas y un poco caídas, con un canal enmedio y que tenga gran espacio del un cuadril al otro, las pospiernas largas y anchas, con los huesos bien hechos y con mucha carne de dentro y de fuera y si tiene los corvejones anchos y extendidos y las canillas cortas y anchas (como el ciervo conforme a razón) fuera veloz y muy diestro, pero teniendo las ancas y los corvejones cortos y las canillas extendidas, será naturalmente caminador. La cola llena de cerdas y larga, con el mástil de ella grueso de justa medida y bien puesto entre las piernas, no obstante que algunos quieren decir, sean ralas las cerdas y si fueren crespas es señal de estima y yo estoy de este parecer. Los compañones y miembros chicos y bien que caballos hay de precio con grandes. Pero yo hallo (según la verdadera razón de filosofía y según las más de las veces, la experiencia lo muestra) que todos los miembros han de corresponder a la grandeza del cuerpo". ${ }^{51}$

Y a continuación el de la jineta, de tamaño menor y, sobre todo, veloz y ágil para la carrera y las rápidas evoluciones, con mucho meneo de extremidades, pero nunca demasiado nervioso:

"Ha de tener mediano el cuerpo y bien hecho, no cargado en la delantera, ni muy descargado, bien bajo, no demasiado, buena cola y crin, buenos bajos, corto de brazos, las cernejas largas y de allí para arriba lampiño, buen rostro y ojo, buen cuello reposado, buena boca, que pare trocados los brazos, el correr menudo, sobre los pies levantado, no gacho, el rostro bien puesto, la boca cerrada, claro, que no se detenga corriendo la carrera, que vaya a ella manso y vuelva sobre los pies, que sea concertado en los galopes, que vuelva a una mano y a otra corriendo sin saltos, que juegue las cañas y esté quieto en el puesto, esto ha de tener un caballo para que se llame bueno de la jineta, que tener de estas cosas alguna buena, en particular sólo ésta se puede loar y no llamar al caballo que tuviere especialmente buen talle, correr y parar como está dicho, huello y sosiego, bueno, y al que esto tuviere sólo se le puede llamar con muy justa causa. Porque corriendo bien el caballo, teniendo buena boca y siendo sosegado, se le puede fácilmente mostrar lo demás". ${ }^{52}$

En cuanto a la manera de estar sentado sobre el corcel, lo típico de la jineta era, como ya se ha dicho, el uso de estribos cortos y anchos, a fin de ponerse el caballero parado sobre ellos:

"Los estribos, soy de opinión vayan más cortos que largos, por tres razones: La una porque yendo corto, va más galán y más recio, porque si está un hombre en pie, más señor es de sí que no sentado, y se puede levantar sobre los estribos y hacer cualquier

51 Ibídem, págs. 21 y 22.

52 Ibídem, pág. 23. 
cosa más bien hecha que yendo largo e irá más cerrado corto y herirá más al caballo [...] Los pies mientras más delanteros es mejor y arrimadas las puntas a las cinchas y el talón hacia afuera y abajo lo más que pudiere, porque con esta costumbre le quedará muy buena postura y muy galana, las rodillas cerradas, sentado sobre el arzón trasero, de manera que quede concavidad entre el arzón delantero y el cuerpo, porque mientras esté más sobre el arzón trasero, estará más bien puesto, más fijo, más galán y el cuerpo más airoso", ${ }^{53}$

y poder así "batir" — golpear continuamente — con los pies sobre los costados del animal:

"Una de las mayores y más principales habilidades y más necesarias de cuantas se hacen en la jineta es batir con los pies a un caballo y para participar de esta habilidad con desenvoltura y gala, es necesario tomar la postura que antes tengo dicha y seguirse por aquella orden hasta que los pies hayan hecho hábito de aquella postura porque quedan con costumbre que aun paseándose con descuido muestran gala, parecen muy bien y hállanse fáciles después en cualquier cosa, y así se podrá ir aprendiendo a espacio, ejercitándose con una continua afición y para que esto venga a efecto, ha de ir siempre en aumento la afición, porque con ella se aprende mucho, lo que no se hará al contrario". ${ }^{54}$

Lo característico de la brida era, en contraste, los estribos mucho más largos, a modo que el hombre fuera sobre el caballo prácticamente de pie, derecho. Sin embargo, Suárez de Peralta apuntaba con insistencia en que de cualquier modo no fuera demasiada esa largura de estribos, a fin de conseguir un mayor dominio del bruto. Total. Lo que importaba, más que nada, era la donosura de quien, cabalgando a la brida, salía a la plaza con el afán de lucir sus habilidades en el difícil manejo del caballo. En esta escuela, pues, comentaba:

"Los estribos no han de ir largos, sino cortos y de los dos extremos paréceme mejor ir corto que largo, pero no sea demasiado, porque irá más fijo y más galán, las puntas de los pies y los estribos para adentro y delanteros un poco (más que traseros) hacia el codillo del caballo, porque si van traseros es feo y falso; y cuando sea menester le ayudará con ellos, según la necesidad y esto a tiempo como se dirá, los pies y estribos vayan (y estén) derechos a la nariz del caballo que casi con la vista (sin ladearse) los vea. Tenerse han las aciones debajo de la rodilla porque así andarán más gallardos, más sueltos y más de maestros, para ayudar al caballero en los saltos y en el manejo, y esto es lo que hoy día se acostumbra". ${ }^{55}$

53 Ibídem, pág. 42.

54 Ibídem, pág. 45.

55 Ibídem, págs. 68 y 69. 
Mientras el jinete iba un poco trasero sobre los lomos de su montura, el bridón por su parte se adelantaba un tanto al acomodarse en la silla. Tocante al imperio del animal por medio de las riendas, cabe apuntar que mientras en la jineta éstas irían más bien sueltas, la técnica de la brida exigía absolutamente conservarlas tensas. ${ }^{56}$

Por lo demás, no podía considerarse que el ser buen caballista resultara nunca cosa sencilla, ni mucho menos. Para llegar a convertirse en eso se precisaba, por lo pronto, mucha paciencia y mucho entusiasmo por la empresa. Suárez de Peralta explicaba así los requisitos que, según él, eran indispensables para pretender adelantar en la carrera:

"Y el caballero que quisiera ser buen hombre de a caballo perfecto, ha de tener tres cosas que cualquiera de ellas en particular no es nada. La primera, tener gran afición a los caballos, curarlos y regalarlos y la otra, no cansarse ni enfadarse de correrlos, que si fuese necesario todo el día correr (de ello) no reciba pesadumbre alguna, porque mientras más carreras, más aprenderá y se soltará en la silla y tomará desenvoltura, con que después venga a hacer lo que quisiere más fácilmente. La tercera es, que siempre entienda que no sabe nada y que ha menester documentos y se huelgue de traerlos de cualquier caballero que algo entendiere, porque en todas las cosas del mundo es esta parte buena y muy virtuosa, tomar siempre consejos y parecer de todos y huír de la afectación en lo que hiciere porque con ello se dará fastidio y no parecerá bien nada de su desenvoltura, ni es posible tenerla con la afectación y los efectos que de ello salen, paran en los extremos y dejan el medio, que es el que se ha de procurar, pues da a todas las cosas gracia y perfección, y al que esto hiciere le aprovechará su trabajo". ${ }^{57}$

\section{Los libros del capitán indiano Bernardo de Vargas Machuca}

En cuanto a la biografía del capitán Bernardo de Vargas Machuca, aquí sólo habré de recordar que, nacido en Simancas alrededor de 1555, recorrió extensas zonas de la geografía mundial en servicio de su patria. Combatió en la propia península ibérica a los moriscos sublevados y en Italia, y luego en diferentes armadas contra el turco en el Mediterráneo y contra los piratas ingleses en el Atlántico y el Pacífico. Anduvo más tarde en diversas entradas sobre los indios insumisos de la Nueva Granada, y por último desempeñó los cargos de alcalde mayor de Portobelo y de goberna-

56 Ibídem, pág. 70.

57 Ibídem, págs. 43 y 44. 
dor de la Isla Margarita. Aparte de sus escritos sobre la caballería, es autor de Milicia indiana y descripción de las Indias (Madrid, Pedro Madrigal, 1599) y de unas Apologías y discursos de las conquistas occidentales, inéditas hasta 1879. Falleció en Madrid el 17 de febrero de 1622, cuando se aprestaba para pasar a servir en otra gobernación americana. ${ }^{58}$

Según él mismo comenta en el prólogo al Libro de exercicios de la gineta, fue durante sus años americanos cuando "cursó y aprendió" los secretos de la equitación. ${ }^{59}$ Mas, a lo que dice, fue ya de vuelta en España y a instancias de varias personas, muy paticularmente de don Alberto Fúcar, que se dedicó a poner en el papel lo que tenía aprendido sobre la materia, y pasó enseguida a publicar sus apuntes, mismos que salieron a la luz durante 1600 en la misma imprenta madrileña que un año antes su libro de la Milicia. La portada del tratado entonces aparecido llevaba el siguiente enunciado: "Libro del Exercicios/ de la Gineta,/ compuesto por el Capitán D. Bernardo/ de Vargas Machuca, Indiano, natural/ de Simancas en Castilla/ la Vieja./ Dirigido al Conde Alberto Fúcar./ [escudo de Fúcar]/ En Madrid,/ Por Pedro Madrigal,/ [filete]/ Año MDC".

Despuès del desempeño de las actividades gobernadoras que lo ocuparon durante los tres primeros lustros del siglo XVII, y una vez instalado de nuevo en la capital de España, sacó don Bernardo el siguiente de sus volúmenes sobre temas de equitación, cuya portada rezaba así: "Teórical y exercicios del la Gineta, primores, secretos, y/ advertencias della, con las se-/ ñales y enfrenamientos del los cavallos, su curación y beneficio./ Por el Governador Don/ Bernardo de Vargas/ Machuca./ [viñeta] / Con privilegio./ En Madrid por Diego Fla-/ menco./ Año 1619”. Revisando el contenido de este tomo, fácilmente se encuentra que no es sino una nueva publicación del Libro de exercicios... de 1600, con las modificaciones de haberse cambiado la colocación de algunas de sus partes, hecho ciertos agregados e incorporado determinadas figuras para auxiliar en la comprensión de su texto. Asimismo, el conde de Villamediana, en la carta que sirve de prólogo a este escrito, insiste en lo bueno de que aparezca en estampa "segunda

58 Una buena biografía de Vargas Machuca es la compuesta por Enrique Otero D'Costa: "Biográfica disertación sobre el capitán don Bernardo Vargas Machuca", en Revista de Indias, Madrid, año XII, enero-marzo de 1952 , n. ${ }^{\circ} 47$, págs. 49-79. Al estudio de la vida y la obra de este mismo personaje dediqué mi tesis de doctorado en historia por la Facultad de Filosofía y Letras de la Universidad Nacional Autónoma de México: Con la espada y con la pluma, el caballo y el compás. Bernardo de Vargas Machuca, un español baquiano de fines del siglo XVI y principios del XVII, México, 1987, 701 págs.

59 Vargas Machuca: Libro de exercicios..., foja sin número. 
y más veces", lo que viene a confirmar la certeza de que tanto para el autor como para sus lectores el trabajo representaba una nueva edición del aparecido el año de cambio de centuria.

Una parte de la tirada de la Teórica y exercicios... vino sin la dedicatoria que de ella hizo Bernardo al conde de Villaflor; así, por ejemplo, pasa con el ejemplar Raros 7830 de la Biblioteca Nacional de Madrid, que es el que yo consulté microfilmado.

Finalmente, fue en 1621 cuando vio la luz el tercer libro de nuestro hombre tocante a las técnicas caballerescas, cuarto y último de los que publicó en vida; así iba su portada: "Compendio,/ y doctrinal nueva de lal gineta./ Dirigido al Prín-/ cipe nuestro Señor don Fe-/ lipe Quarto./ Por el governador/ Don Bernardo de Vargas/ Machuca./ [viñeta] / Con privilegio./ En Madrid. Por Fernando/ Correa de Montenegro./ Año de 1621”. Este folleto, en realidad, pretendía ser algo así como un natural epílogo a todo lo anterior escrito sobre la materia por don Bernardo en el cual, aparte de asentar unos cuantos apuntamientos que le parecía faltaban en sus trabajos anteriores quería dar, en resumen, la que para él era, precisamente, $s u$ doctrina personal — su teoría, digamos o, exagerando un poco las cosas, "su filosofía" - sobre ciertos aspectos de la forma más característicamente hispana de andar a caballo.

De la tercia de obras sobre la jineta escritas por quien por su muerte no llegó a desempeñarse como gobernador de Antioquia, Cáceres y Zaragoza en el Nuevo Reino de Granada, sólo uno ha vuelto a ser editado, la Teórica y exercicios..., el más extenso de ellos, el cual publicó en Madrid la segunda época de la Sociedad de Bibliófilos Españoles en el curso de 1951, en unión de los ya citados Discurso... de Juan Arias Dávila Puertocarrero y el Del modo de pelear a la gineta de Simón de Villalobos y Benavides, con un buen prólogo del veterinario Cesáreo Sanz Egaña y en un volumen que se nombró Tres libros de jineta de los siglos XVI y XVII, en el cual se modertniza la ortogrtafía de los textos originales.

A partir del conocimiento que sobre ella ha adquirido a través del tiempo, va a exponer Bernardo ante sus contemporáneos la práctica y la teoría de la caballería. No era muy modesto cuando aseguraba a Felipe IV, en el ofrecimiento de su Compendio y doctrina nueva, que las que él allí exponía eran ideas de verdad bien meditadas y novedosas. ${ }^{60}$

60 Vargas Machuca, Bernardo de: Compendio y doctrina nueva de la gineta. Dirigido al Príncipe nuestro Señor don Felipe Quarto. Por el governador Don..., Madrid, 1621, + 26 fojas, foja sin número. 
Practicar la caballería era una forma de ensayarse para la guerra, actividad esta última en la cual era en la que eminentemente podían los hombres reiterar o incluso hasta alcanzar la nobleza, es decir, presentarse ante sus congéneres como un ejemplo de lo que su propia sociedad exigía de cada quien como paradigma de comportamiento:

"no pueden los nobles y generosos Cavalleros essentarse de los exercicios de armas, assí a pie como a cavallo, pues mediante ellos restauran lo que pudo faltar en sus antecessores, o quando en ellos aya sobrado la nobleza, sustentan la obligación mayor que tienen a no degenerar de su profesión, continuando en el estilo que sus pasados con tanto honor mantuvieron: y esto sirviendo a sus príncipes [...]". ${ }^{61}$

Fundamentalmente, lo que se encuentra en estos textos de don Bernardo de Vargas son unos consejos útiles que él ha querido proporcionar a sus colegas caballeros, buscando siempre facilitarles el ejercicio de esa profesión suya tan querida. Lo que él desea, es poner ante la consideración de quien lo acepte por su maestro todo el caudal de su propia experiencia, de modo que en las páginas de sus libros encuentre solución a la totalidad de sus dudas. Y así, llega a asegurar con jactancia cómo los estudiosos podrán encontrar

"todo remedio en este tratado, si con curiosidad y diligencia se valieren dél, ansí en el presente freno [-dice cuando trata del enfrenamiento- - como de lo demás que adelante diremos". ${ }^{2}$

Pero tampoco deja de apuntar que sus lecciones habrán de tomarse siempre con buen discernimiento, de modo que, si resulta del caso, se introduzcan en ellas las modificaciones pertinentes. No trata de ser dogmático, sino que más bien su pretensión es la de exponer llanamente su doctrina para que, a partir de ella, mediante su propio estudio y razonamiento, el jinete decida por sí propio lo que juzgare más oportuno en cada momento. Y así, por ejemplo, dice en una ocasión en la Teórica y exercicios de la gineta, mientras se está refiriendo a los problemas de la colocación de los frenos:

"Con estas advertencias acerca del enfrenamiento, el caballero discurra y estudie, y sea curioso, porque cualquiera parte que le falta hallará el remedio con el buen entendimiento y estudio, aplicando otra que le parezca y enmiende la falta que por nuevas causas y alteraciones dellas suelen quedar mancos los efectos". ${ }^{63}$

61 Vargas Machuca: Libro de exercicios..., foja sin número.

62 Vargas Machuca: Teórica y exercicios..., pág. 140.

63 Ibídem, pág. 145. 
Sobre esta misma advertencia vuelve luego en la última página de la Teórica... Todo puede mejorarse. Sus enseñanzas no son reglas que deban acatarse sin discusión, sino sólo opiniones bien fundadas que de todos modos pueden superarse, pues continuamente se ha de procurar avanzar en el conocimiento y en el desempeño de estos menesteres hípicos. ${ }^{64}$

Insiste mucho Vargas Machuca en que sus conceptos pueden resultar discutibles; pero, con todo, también desea dejar bien claro que ellos los ha deducido después de una enorme práctica - de cuarenta años, nada menos, afirma en el Compendio..., de 1621-, por lo que no pueden ser despreciados por nadie sino despuès de maduros juicios y pruebas contundentes de su ineficacia. Así expone, al ofrecer este libro a don Felipe IV, cuál considera que es el sustento todo del discurso suyo sobre la cuestión:

"Las partes esenciales de la gineta, serenísimo príncipe, constan de teórica y prática, que si bien no es ciencia fundada en principios necessarios por sí conocidos y regulares, y permanentes tienen por fundamento una razón natural, aprovada en el común sentimiento de los más aventajados discursos en q. el mío ha militado por espacio de quarenta años, procurando darle realzes, y ha descubierto, q. consiste en doze consideraciones tan sustanciales, dirigidas a su fin, q. bien observadas le darán perfeto dividiéndose en otras tantas partes, que constituyen el natural compuesto del hombre". ${ }^{65}$

La verdad es que en estas líneas que acabo de transcribir se encuentra todo el sentido del pensamiento de don Bernardo con respecto a la jineta en cuanto a teoría: ella no puede ser otra cosa que una especulación sobre la materia, basada en la experiencia, sin ambiciones de validez absoluta, pero sí con la pretensión de establecer principios útiles para la vida práctica, vale decir, para el adecuado desempeño de los ejercicios propios de ese tipo de monta. Por lo demás, el cómo había que practicar la caballería jineta, el quid en el que radicaba el secreto de su perfección, lo explicaba el capitán Vargas Machuca con estupenda puntualidad en la frase puesta debajo de la ilustración del caballero alanceador que aparece así en la portada del Libro... cuanto en la de la Teórica...: "Primor con fuerza", idea la cual reiteraba en el texto de esta última obra, cuando decía "que acompañando la fuerza con el primor es el verdadero fundamento de la jineta". ${ }^{66}$

Total. Lo importante en quien sube al caballo es el empeño que demuestra en salir bien en sus evoluciones, la voluntad con la que acude a

64 Ibídem, pág. 270.

65 Vargas Machuca: Compendio..., fojas 1 y $1 \mathrm{v}$.

66 Vargas Machuca: Teórica y exercicios..., pág. 132. 
cumplir con su obligación de verdadero aristócrata. Si falla, por ejemplo, al alancear un toro, tal cosa pudo deverse a la mala fortiuna, de modo que si él, por su parte, hizo todo lo que estaba a su alcance para realizar con precisión la suerte, no deberá ser culpado "entre los discretos y científicos en esta profesión". ${ }^{67}$

Lo que sí, que el caballero, el hombre de a caballo, para serlo de verdad, ha de atender al cumplimiento de determinados deberes inexcusables: el de ocuparse de su montura personalmente, procurando su cuidado por buenos criados y albéitares a los cuales, siempre, habrá él de vigilar de cerca pues, como apunta el castellano viejo de Simancas, "es muy verdadero aquel refrán que dice: al ojo del amo engorda el caballo"; 68 y asimismo, el de buscar siempre el pleno dominio sobre su animal. Esta es la última recomendación de nuestro autor al dar punto final a su Compendio y doctrina nueva..., expresándola con las siguientes enfáticas palabras:

"y despidiéndome del assunto deste compendio y advertencias por aora, encargo sobre todo al cavallero para que más luzga lo que assí obrare,que procure siempre se le rinda el cavallo en que se pussiere, porque de lo contrario no se puede esperar otro que contrarios efetos y sucessos". ${ }^{69}$

67 Ibídem, pág. 221.

68 Ibídem, pág. 254.

69 Vargas Machuca: Compendio..., foja 26v. 